\title{
Artigo
}

\section{A representação dos banqueiros no Brasil: um estudo sobre a FEBRABAN}

\author{
Rodolfo Palazzo Dias \\ Mestre pela Universidade Estadual de Campinas, \\ Doutorando pela Universidade Federal de Santa Catarina, \\ Pesquisador do Núcleo de Estudos Sociopolíticos do Sistema Financeiro \\ (NESFI) do Departamento de Sociologia e Ciência Política da UFSC \\ rodolfo.dias@gmail.com
}

\begin{abstract}
Resumo: Nosso artigo terá por objeto de análise a FEBRABAN enquanto instituição representativa dos banqueiros no Brasil. O trabalho será dividido em 4 partes. Na primeira parte faremos uma análise da constituição histórica da entidade. Na segunda, apresentaremos algumas mudanças institucionais que ocorreram entre as décadas de 1990 e 2000, destacando a diminuição da importância das associações representativas regionais, em favor da representação direta dos bancos. Em um terceiro momento, apresentaremos a estrutura institucional da FEBRABAN. Por último, faremos considerações sobre o papel da FEBRABAN no processo de socialização dos banqueiros, apontando possibilidades para futuras pesquisas. Percebemos que a entidade não manifesta oficialmente posicionamentos relacionados a temas de importância política; seus documentos e seus representantes possuem um foco nos problemas institucionais e administrativos dos bancos e da própria entidade. Nossas principais fontes de pesquisa foram documentos coletados na FEBRABAN durante os anos de 2009 e 2010, como relatórios, atas, e materiais de divulgação da entidade, que permitiram a identificação de organogramas, regras institucionais e posicionamentos dos banqueiros. Também fontes secundárias foram fundamentais para a realização da pesquisa, principalmente na análise histórica. Percebemos que a coesão é uma característica marcante dos banqueiros; que sua estrutura representativa está nacionalizada sob a forma de "associação civil"; e que sua função representativa não seria a de um "porta-voz" dos bancos para a sociedade, o papel de socializar os banqueiros entre si se mostra bastante relevante em nossa pesquisa.
\end{abstract}

Palavras-chave: FEBRABAN; banqueiros; associação empresarial; representação.

\footnotetext{
Abstract: Our article will have by object of study FEBRABAN as representative institution of bankers in Brazil. The work will be divided into 4 parts. In the first part we will analyze the historical constitution of the entity. In the second one, we will present some institutional changes that occurred between the 1990s and 2000, highlighting the decreased importance of regional representative associations, in favor of direct representation of banks. In a third step, we will present the institutional structure of FEBRABAN. Finally, we will discuss the role
} 
of FEBRABAN in the socialization process of bankers, pointing out possibilities for future researches. We realize that the entity officially not manifested positions about political issues; their documents and their representatives discussed institutional and administrative problems, focusing the banks and the institution itself. Our principal sources of research were documents of FEBRABAN, collected during the years 2009 and 2010, as reports, minutes, and promotional materials of the entity; which allowed the identification of organizational charts, institutional rules and positions of bankers. Secondary sources were also crucial in the research, especially in historical analysis. We conclude that cohesion is a striking characteristic of bankers; its representative structure is nationalized in the form of "civil association"; and its representative function would not be a "spokesman" of the banks to society, the role of socializing bankers among themselves showed to be quite relevant in our research.

Keywords: FEBRABAN; bankers; entrepreneurs' association; representation.

\section{Introdução}

Apresentamos aqui os resultados de uma pesquisa que buscou tratar um tema geralmente colocado à margem nos estudos empresariais brasileiros na área da Ciência Política, os banqueiros. Tal campo possui uma grande carência de pesquisa, e por isso desejávamos explorar tanto os aspectos organizacionais destes como também seu posicionamento diante dos grandes temas políticos na atualidade (especificamente dentro do governo Lula).

Inicialmente, acreditávamos que tal pesquisa poderia ser realizada através de um estudo da principal instituição dessa camada de empresários, a FEBRABAN. Porém, durante o desenvolvimento da pesquisa, percebemos que a FEBRABAN não é um espaço no qual os banqueiros buscam criar um posicionamento comum nem divulgar esse posicionamento. Em seus documentos, seja nas Assembleias Gerais, seja nas reuniões da Diretoria Executiva, ou nos documentos publicados pela entidade, não identificamos a formulação e um posicionamento político claro dos banqueiros diante dos temas políticos de maior relevância. Nossa pesquisa sobre FEBRABAN não nos revelou aspectos do posicionamento político dos banqueiros.

Tal fato surpreendeu nossas hipóteses, já que nos estudos tradicionais de empresários na ciência política, as instituições representativas geralmente assumem esse papel de "falar" em nome da fração representada. No presente artigo apresentaremos parte dos resultados de nossa pesquisa sobre a organização dos banqueiros. Desenvolvemos nosso texto lançando a seguinte pergunta: se a FEBRABAN não é um "porta-voz" dos banqueiros, qual é a sua importância enquanto instituição representativa? Consideramos 
que, para problematizar o objeto de estudo nesse sentido, precisamos de um conceito específico de representação.

Sobre o tema, é interessante o trabalho realizado por Kinzo (1978), que mostra uma certa variedade de abordagens nas definições clássicas de representação, mas identifica um elemento comum entre elas: a separação entre representantes e representados. Observamos em nosso estudo sobre FEBRABAN que não são os aspectos desvinculados da sua base aqueles mais marcantes da instituição. Como seria, por exemplo, a manifestação pública de uma opinião política específica utilizando apenas o nome da entidade, se distanciando das empresas às quais representa.

Percebemos que dentro da FEBRABAN o aspecto socializador da entidade assume um grau de importância maior. Consideramos necessária a utilização de um conceito de representação que destaque a interação entre representantes e representados, e não sua separação. Assim sendo, o conceito de representação exposto por Gramsci na seguinte passagem se mostra bastante útil:

Se a relação entre intelectuais e povo-nação, entre dirigentes e dirigidos, entre governantes e governados, é dada graças a uma adesão orgânica, na qual o sentimento-paixão torna-se compreensão e, dessa forma, saber (não de uma maneira mecânica, mas vivida), só então a relação é de representação, ocorrendo a troca de elementos individuais entre governantes e governados, entre dirigentes e dirigidos, isto é, realiza-se a vida do conjunto, a única que é a força social (Gramsci, v. 1, Q 11, §67: 222).

Essa passagem apresenta um conceito de representação que destaca a importância da participação e interação dos representados com os representantes. Os laços orgânicos, vividos, dos banqueiros entre si dentro da instituição, são o objeto de estudo quando mobilizamos tal conceito.

Portanto, quando buscamos identificar o grau de representatividade da FEBRABAN em relação aos banqueiros, não devemos pensar no nível de concessão ou autoridade que estes cedem à entidade, mas sim em que medida a entidade é capaz de integrar e socializar os banqueiros entre si. A FEBRABAN, sob essa perspectiva conceitual, será analisada mais como um espaço de interação entre agentes do que como um ator político separado. 


\section{Formação histórica da FEBRABAN}

A história do associativismo bancário é a mais longa dentre as associações de entidades financeiras brasileiras. Desde a década de 1920, pudemos observar o surgimento de associações de bancos no Brasil. Uma variável que é marcante nos processos iniciais de criação de associações de bancos no Brasil são as transformações do sistema financeiro que, em geral, ocorrem em um período próximo a essa organização.

O processo de organização das associações regionais (no caso da Associação dos bancos do Estado do Rio de Janeiro [ABERJ] em 1922 e da Associação dos bancos do Estado de São Paulo [ASSOBESP] em 1924) foi marcado pelas transformações do sistema regulatório da época. Segundo o documento comemorativo de 40 anos da FEBRABAN, esse associativismo

surgiu quase em resposta às importantes regulamentações que mexeram com o setor bancário naqueles anos - como a Seção de Compensação de Cheques, de 1919; a inspetoria Geral de Bancos, órgão fiscalizador, de 1921; e a Carteira de Redesconto do Banco do Brasil, também de 1921 (FEBRABAN, 2007, p. 12).

O mesmo aconteceu com a associação nacional dos banqueiros, a FEBRABAN. Durante a década de 60 houve o golpe militar no Brasil, que, além das consequências políticas repressivas características de uma ditadura, também alteraram profundamente o sistema econômico nacional em geral e o sistema financeiro em específico.

A alteração ressaltada pelo documento de 40 anos da FEBRABAN foi a Lei 4.595 de 1964, também chamada de "Lei da Reforma Bancária". Segundo Costa (2008), esta lei modificou o cenário financeiro brasileiro através da mudança dos marcos regulatórios da atividade bancária, com especial destaque para a criação do Banco Central do Brasil (embora tenham sido mantidas algumas funções de autoridade monetária com o Banco do Brasil). Em 1964 também surgiram outras leis que transformaram o sistema financeiro nacional e que criaram o FGTS (Fundo de garantia do tempo de serviço), o Banco Nacional de Habitação (BNH), e instituíram a correção monetária para depósitos em poupança e empréstimos imobiliários (Costa, 2008: 342). Também no mesmo ano houve a criação do Programa de Ação Econômica do Governo (PAEG), que segundo o documento de 40 anos da FEBRABAN teve impacto no setor bancário através de medidas 
de combate à inflação como: "correção monetária, seguidas desvalorizações da moeda, arrocho salarial e corte se subsídios, entre outras" (FEBRABAN, 2007: 8).

Foi nessa década que os banqueiros começaram a se reunir nos Congressos Nacionais dos Bancos. Na época, a representação dos banqueiros era muito regionalizada. Ary Minella (1988), em seu estudo sobre banqueiros nesse período, elege a ASSOBESP, em vez da FEBRABAN (associações de caráter civil), e a SBERJ (Sindicato dos Bancos do Estado do Rio de Janeiro), em vez da FENABAN (Federação Nacional dos Bancos) (associações de caráter sindical) como objeto de estudo, pois, segundo o autor, as primeiras controlavam na prática as segundas (Minella, 1988: 14).

O processo de organização nacional dos bancos foi realizado por suas associações regionais. Além dessa característica, percebemos na divisão realizada por Minella um controle da representação sindical pelos banqueiros cariocas e um controle da representação civil pelos banqueiros paulistas.

O primeiro congresso ocorreu em 1960, na cidade do Rio de Janeiro. Segundo Minella:

O I Congresso Nacional dos Bancos foi realizado num contexto muito especial. Dois elementos-chave influíram em sua realização: o movimento sindical ascendente dos assalariados bancários e a conjuntura política, ou seja, a transição do governo Juscelino Kubitschek ao governo Jânio Quadros (1988: 253).

Antes da década de 1960, a representação dos banqueiros consistia basicamente em uma série de associações regionais; durante a década de 1960, a conjuntura política do Estado e da relação com os trabalhadores incentivou os banqueiros a dialogarem em um âmbito nacional.

O órgão sindical nacional dos banqueiros, a FENABAN, foi criada em setembro de 1966 (FEBRABAN, 2007: 11), ano no qual não houve um Congresso Nacional dos Bancos. No ano seguinte, 1967, houve o VI Congresso Nacional dos Bancos, no qual houve a criação da FEBRABAN.

Para analisarmos essa conjuntura de organização dos banqueiros, é interessante retomarmos as considerações de Alvaro Bianchi a respeito dos motivos que incentivam empresários de um modo geral a se organizarem. 
Segundo Bianchi, existiriam motivações gerais dentro do sistema econômico e político que incentivariam os empresários a se organizar coletivamente. Segundo o autor, a organização empresarial é motivada: a) pela tentativa de conter certas práticas, originárias das relações de concorrência, as quais podem comprometer a viabilidade do sistema econômico; b) pelo enfrentamento que os empresários possuem com os trabaIhadores; e c) pela necessidade de influenciar o Estado (Bianchi, 2010: 37-39).

Mas como lembra o autor:

A separação desses três conjuntos de relações acima apresentados - dos empresários entre si, com a ação coletiva dos trabalhadores e com o Estado - só é possível com fins meramente analíticos. Nos processos históricos reais, eles se encontram entrelaçados de maneira complexa e indissolúvel (2010: 39).

Os Congressos Nacionais dos Bancos mostram empiricamente como essas relações se processam conjuntamente na história. Minella realizou um estudo sobre as teses discutidas dentro desses congressos, envolvendo os realizados entre os anos de 1960 até 1981, totalizando 14 congressos. A tabela elaborada pelo autor sobre as teses é apresentada a seguir: 
Quadro S.2 Congressos nacionais de bancos - Distribuiçäo temáticas das teses

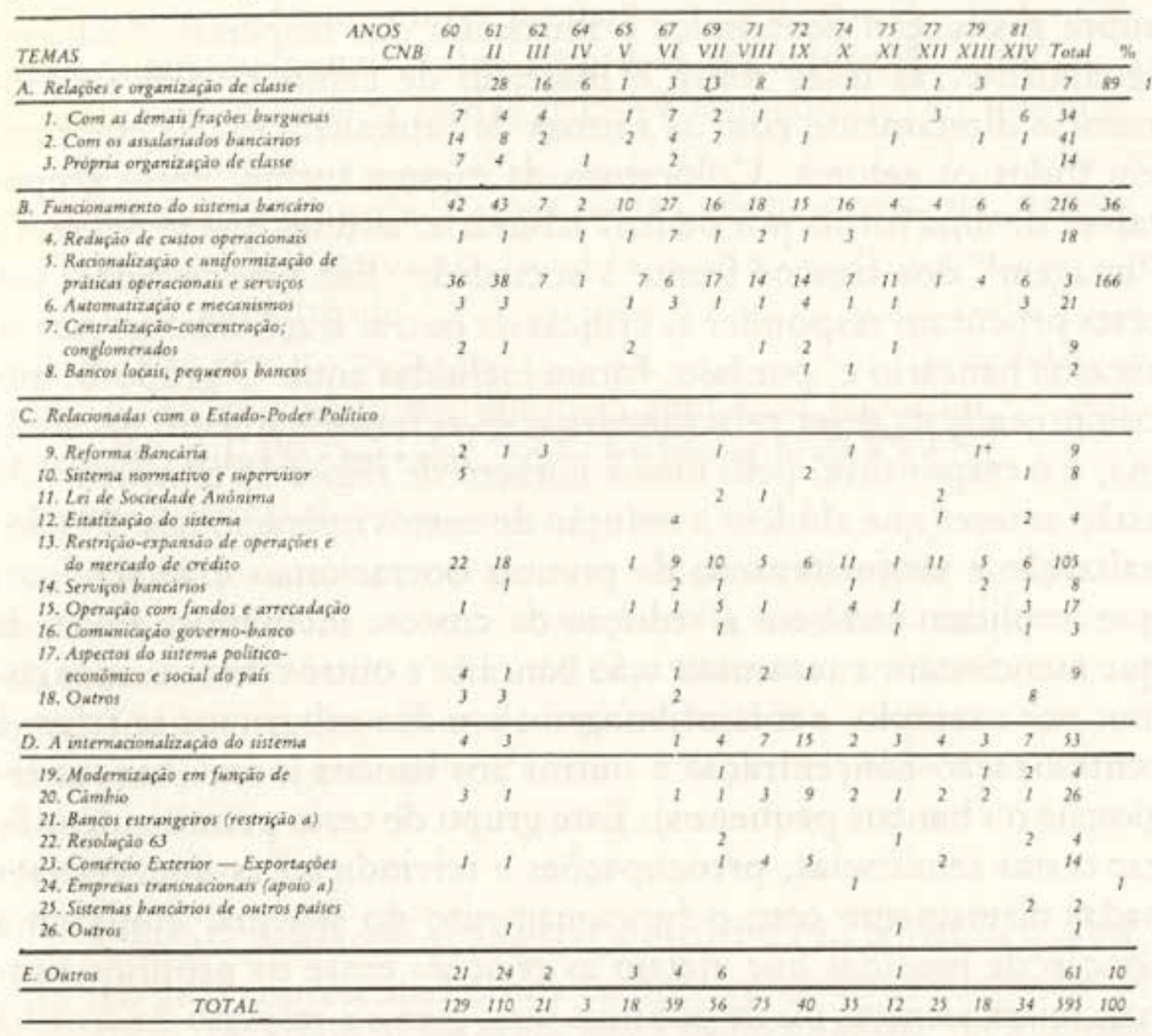

Fonte: Elaboralo a partir de Anais do CongressosNacionais de Bancos e Sindicato dos Bancas de Minas Gerais e Associasado de Bancos do Eutado de Minat Gerais, Levantamento das teses dos congressos anteriores, trahalho appesentado no X7 CNB, 1975.

Obs. Dades incompletes sobre o II, $I I I$ e $I V \mathrm{CNB}$

"Retirada

Fonte: Minella (1988: 270).

Somando todos os congressos, Minella identificou 41 teses que discutiam a relação dos banqueiros com os trabalhadores bancários (item 2). Somando os três primeiros congressos (1960, 1961 e 1962), foram ao todo 24 teses. Ou seja, mais da metade das teses sobre trabalhadores foram discutidas nos três primeiros anos de Congresso.

Isso mostra que o tema "trabalhadores" foi um fator que impulsionou os banqueiros a se organizar nacionalmente, embora posteriormente tenha perdido força (também temos que levar em consideração que em 1964 houve o golpe militar e o início de uma política de repressão). 
Outro fator que consideramos importante e que impulsionou os banqueiros a se organizar nacionalmente foi a relação destes com o Estado. Como já foi falado, em meados da década de 1960 observamos uma série de alterações que incidiram sobre o sistema financeiro. Durante os Congressos, a relação dos banqueiros com o Estado foi um tema especialmente debatido dentro dos congressos, com especial destaque para o tema: "restrição - expansão de operações e do serviço de crédito" (item 13), tema esse que possuiu ao todo 105 teses discutidas durante todos os congressos.

A forma como é caracterizado o nascimento da FEBRABAN em seu documento comemorativo de 40 anos também apresenta a importância desse fator. Com o primeiro capítulo intitulado "Nascendo da necessidade", o texto passa a descrever as mudanças que o governo realizou na economia e no sistema bancário, destacando a influência desses no processo de organização dos banqueiros. Percebemos, assim, que o processo de organização dos banqueiros naquele período é marcado pela construção de formas específicas de relacionamento dos mesmos com o Estado.

O terceiro fator de incentivo à organização dos banqueiros, que seria a criação de um tipo de relacionamento entre os próprios banqueiros, também é uma variável bastante relevante. Tal fator está ligado ao estabelecimento de padrões operacionais da atividade bancária no Brasil. Os órgãos reguladores da atividade estavam surgindo, e padronizações dentro do sistema bancário estavam sendo encaradas como uma necessidade. Segundo o relato de Olavo Setúbal, sobre o VI Congresso Nacional dos Bancos:

Eu tinha levado a tese de que não deveríamos cometer o mesmo erro das estradas de ferro, que têm não sei quantas bitolas no Brasil, um tumulto completo. Já tinha banco com o sistema americano, havia bancos com o sistema europeu, e eu levei uma proposta para adotar o sistema de marcação eletrônica europeia, que é a que está em vigor até hoje. A padronização do cheque ia permitir a compensação mais rápida e em melhores condições (FEBRABAN, 2007: 14).

A fala de Olavo Setúbal já mostra que a padronização dos procedimentos da atividade bancária foi um grande problema discutido entre os banqueiros no período. Segundo o estudo de Minella, esse foi um dos temas mais debatidos, com especial destaque para a temática "racionalização e uniformização de práticas operacionais e serviços", com 166 teses (item 5). 
Percebemos que a relação intraclasse foi um dos grandes estimuladores do desenvolvimento da organização representativa nacional dos banqueiros. Essa relação intraclasse não assume apenas um papel de contenção de atividades econômicas predatórias (aspecto de limitação de comportamento econômico concorrencial), mas também de promotor de certo comportamento, em um sentido mais afirmativo. Pensando que estamos tratando de uma época em que o sistema financeiro estava sendo criado (em comparação ao padrão financeiro internacional), consideramos que o processo associativo dos bancos teve um papel fundamental no desenvolvimento da atividade.

Tal processo, além do resultado econômico de transformação do setor bancário, produziu também o diálogo e a união da classe empresarial nacionalmente. Segundo a fala de Geraldo Magela Leite (que em 1960 era presidente da ASSOBESP):

Antes do I Congresso Nacional dos Bancos, no Rio, os banqueiros de São Paulo e do Rio não se conheciam. Quando o sindicato recebeu a Aberj para uma reunião para tratar da constituição do primeiro congresso, o encontro se deu em São Paulo. Ao chegarem os representantes da Aberj, eles não eram conhecidos em São Paulo. Os banqueiros de São Paulo não conheciam os banqueiros do Rio. Eram entidades que existiam independentes umas das outras (FEBRABAN, 2007: 12).

O processo de gestação do associativismo bancário nacional, impulsionado por motivos imediatos como a relação destes com os trabalhadores, e também por motivos mais perenes, como a relação com o Estado e a autorregulação da atividade bancária, gerou a construção de um associativismo nacional, no qual as forças regionais desse empresariado passaram a se relacionar mais constantemente.

A origem das organizações é capaz de nos revelar uma série de aspectos e funções destas no momento atual. Acreditamos que a análise histórica da FEBRABAN nos revela o seu papel na criação de um espaço no qual os banqueiros poderiam se comunicar. Claro que a resolução das pendências conjunturais foi importante nesse processo de mobilização, mas identificamos como grande resultado desse processo a construção do espaço de socialização entre banqueiros. 


\section{Transformações do sistema representativo dos banqueiros}

O sistema representativo dos banqueiros mudou a partir de então. Ele passou a estar mais nacionalizado, com especial destaque para a FEBRABAN enquanto instituição representativa. Se observávamos no período histórico anterior a construção da representação nacional pelas associações regionais dos banqueiros, em nosso período histórico podemos observar a consolidação desse modo nacional de representação associativa em detrimento das representações regionais. É esse o resultado apontado pelas primeiras fontes empíricas analisadas em nossa pesquisa, as atas das Assembleias Gerais da FEBRABAN entre os períodos de 1989 até 2009.

Escolhemos as assembéias para iniciar nossa pesquisa empírica, pois, a princípio, nesse espaço se colocavam os bancos como um todo (e não apenas aqueles eleitos para cargos dentro da administração da Federação). Pelo fato de a Federação ser composta por um conjunto heterogêneo de bancos (bancos públicos, privados, de grande e pequeno porte, nacionais e estrangeiros etc.), acreditávamos que seria nesse espaço que o debate político apareceria. E com isso poderíamos fazer uma análise da posição política da fração bancária dentro do bloco no poder (objetivo primário apresentado no início do artigo).

Não foi isso que encontramos em nossa pesquisa nas atas das Assembleias Gerais. Buscamos deixar claro qual foi a intenção inicial de pesquisarmos as atas para podermos contrastar com o resultado obtido. Das atas lidas, desde 1989 até 2009,1 todos os pontos de pauta levantados foram aprovados por unanimidade. Não havia nenhuma pauta que tenha sido relatada dentro da ata como sendo objeto de debate pelos presentes na Assembleia. Inclusive, todas as eleições desde essa data ocorreram com chapa única, e também todas foram aprovadas unanimemente.

Contrastando nosso objetivo inicial (encontrar e caracterizar os tipos de debates e conflitos existentes dentro da fração financeira) com o resultado da análise (aprovação unânime de tudo que era colocado), queremos destacar a característica mais marcante demonstrada pelas atas das Assembleias Gerais: a grande coesão existente entre os banqueiros.

1 Ao todo, fizemos a análise de 17 atas de Assembleias Gerais ordinárias, e 17 atas de Assembleias Gerais extraordinárias. Totalizando o número de 34 Assembleias Gerais analisadas. 
Com isso não queremos dizer que não existia conflitos. Como identifica Minella durante os Congressos Nacionais dos Bancos: "costumava escamotear-se certos problemas e conflitos entre os banqueiros, procurando estes apresentarem-se publicamente com uma imagem mais consensual possível" (1988: 248).

Essa prática de ocultação do conflito já é prática comum entre os banqueiros. O que as atas das Assembleias nos permitem afirmar é que esses possíveis conflitos são resolvidos em espaços anteriores às Assembleias; e tendo em conta que estamos tratando de atas desde 1989 até 2009, ou seja, 20 anos, o fato de nunca ter surgido um conflito dentro das assembleias já demonstra uma grande capacidade por parte da instituição representativa da fração bancária de coesionar sua base. O sistema de solução de conflitos mostra-se altamente eficiente, tendo em vista que os conflitos não aparecem na instância maior de decisão da FEBRABAN.

Portanto, essa coesão não se remete nem à inexistência de conflito nem se trata de ausência de transformações dentro da instituição representativa. As atas das Assembleias Gerais mostram, de maneira mais ou menos clara, algumas transformações dentro do sistema representativo dos bancos; e mostram como transformações importantes ocorreram sob aprovação unânime.

A primeira grande transformação que chamou nossa atenção foi o processo de mudanças do estatuto social, processo este que vinha correndo desde a década de 1990 e que se consolidou em 3 de junho de 2004. O novo estatuto aprovado nessa data buscava adequar-se ao novo código civil; porém, possuía algumas alterações importantes que vão além da adequação jurídica. A primeira grande alteração a qual chamamos a atenção é a mudança da própria razão social da federação. Enquanto em 1999 a razão social da federação exposta no estatuto social era "Federação Brasileira das Associações de Bancos", atualmente o estatuto social coloca a razão social da entidade como "Federação Brasileira de Bancos".

Essa mudança ilustra o processo ao qual chamamos a atenção no início do tópico, que seria a diminuição da importância das associações regionais de representação dos banqueiros dentro da FEBRABAN. Enquanto durante a década de 1960 observamos um processo de organização nacional realizada a partir das forças regionais dos banqueiros, agora notamos o processo de enfraquecimento dessas forças regionais e a consolidação da forma representativa nacional. 
Nas atas das Assembleias durante a década de 1990 e início da década de 2000, percebe-se a presença das associações regionais dentro do funcionamento da FEBRABAN. Quando havia lista de presentes, os representantes assinavam pela associação à qual estavam vinculados. Quando eram mencionados pela proposição de alguma pauta ou moção, também era pela associação regional a qual representavam que eram tratados.

Foi em 2004 o último momento em que encontramos representantes assinando pelas associações regionais; na Assembleia ordinária de 5 de março, e na Assembleia extraordinária de 3 de junho (nas quais houve a transformação do estatuto social da Federação). Depois desse ano, nas Assembleias posteriores, os representantes passaram a assinar pelo banco ao qual pertenciam.

A principal mudança no estatuto que apontou nessa direção foi a mudança do artigo 1‥ No estatuto social de 1999, este artigo é colocado dessa forma: "Artigo 1ㅇ: A Federação Brasileira das Associações de Bancos agremia entidades representativas das instituições bancárias no Brasil". Já no de 2004, presente na ata da Assembleia extraordinária:

Artigo 1o: A Federação Brasileira de Bancos, regida por este estatuto social e pelas disposições legais aplicáveis, doravante designada FEBRABAN, é uma associação civil sem fins lucrativos, que congrega instituições financeiras bancárias, com atuação no território nacional, e associações representativas de instituições financeiras e congêneres, de âmbito nacional ou regional.

Percebemos através desse artigo que houve uma mudança de foco: enquanto antes a FEBRABAN era composta apenas por associações, os bancos tornaram-se membros no novo estatuto.

Além da mudança no estatuto social, outro fato que nos chamou a atenção foi a incorporação da Associação dos Bancos no Estado de São Paulo (ASSOBESP) pela FEBRABAN. Dada a importância que esta Associação possuía dentro do estudo de Minella (1988), chamou-nos a atenção a forma de sua incorporação. Quando essa entidade regional foi incorporada pela entidade nacional, poderiam ter surgidos problemas principalmente vinculados à questão da representação. Ou os interesses dos banqueiros paulistas poderiam não ser totalmente contemplados pelo fato de a entidade ter um foco nacional, ou os banqueiros de outras regiões poderiam reclamar por ter os 
interesses nacionais interferidos pelos interesses regionais dos paulistas. Tais problemas não surgiram.

Essa incorporação aconteceu durante a Assembleia Geral de 8 de setembro de 2004. Os dois principais argumentos a favor da incorporação foram a economia de gastos e o fato de todos os bancos associados à ASSOBESP serem também associados à FEBRABAN. A possibilidade de tal incorporação já havia sido aprovada em reunião dentro da própria ASSOBESP. O que nos surpreendeu não foi tanto a não existência de conflitos promovidos pelos associados de São Paulo (o que pode ter acontecido nas reuniões existentes na ASSOBESP, sendo que não tivemos acesso a documentos dessas reuniões), mas é marcante a não existência de resistências por parte de bancos que não fossem associados à ASSOBESP. O que significa que, mesmo com a incorporação da instituição pela FEBRABAN, não haveria um interesse regional dos banqueiros paulistas que interferisse na representação nacional.

Dentro da ata da Assembleia que resultou na incorporação da ASSOBESP, as duas justificativas expostas foram: o pertencimento de todos os associados da entidade de São Paulo à FEBRABAN e a necessidade de corte de gastos. O problema da representatividade simplesmente não apareceu na documentação da FEBRABAN.

Portanto, além do aspecto de grande coesão existente dentro da fração bancária, as atas nos permitem afirmar uma progressiva desrregionalização da representação bancária no Brasil, processo esse que culmina com a forte alteração no estatuto social e com a incorporação da ASSOBESP em 2004.

Mas como entender esse processo de desrregionalização, sem ter em conta as transformações da própria fração bancária?

Se analisarmos o setor bancário durante a década de 1990 e a década de 2000, perceberemos que houve o processo chamado na literatura econômica corrente de concentração bancária, mas que pela teoria econômica marxista seria melhor descrito pelo conceito de centralização do capital bancário. ${ }^{2}$ Tal processo geralmente fica claro quando mostramos o gráfico que representa o número de bancos entre dezembro de 1993 e maio de 2010.

2 Segundo Mello (2000: 103-107), os fenômenos de concentração e centralização teriam uma origem comum, que seria o processo de concorrência entre os capitalistas. A concentração seria um conceito que se refere ao aumento do volume de capital na posse de agentes capitalistas; o de centralização se refere à diminuição quantitativa de capitalistas em uma área econômica, produzindo situações de monopólio. Nesse sentido, o conceito de centralização seria mais adequado. Para mais detalhes acerca da relação entre os três conceitos (concorrência, concentração e centralização), ver Mello (2000). 


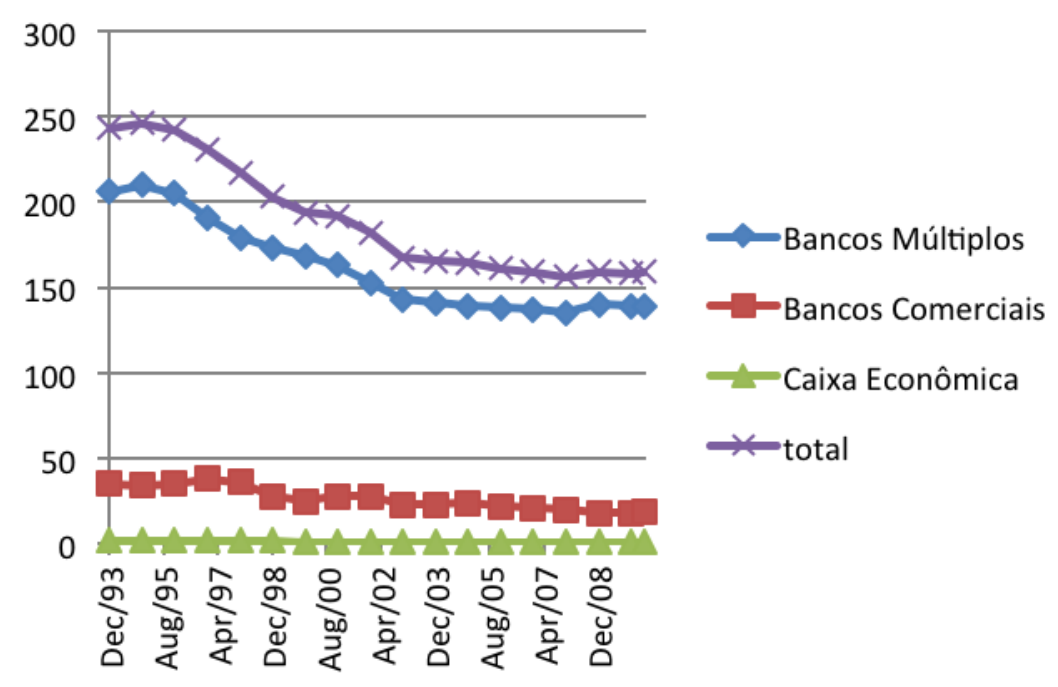

Fonte: Dados após 2001 retirados das atualizações mensais do BACEN; anterior a 2001, retirados de Fonseca e Barbachan (2004).

Percebemos que houve uma diminuição significativa do número total de bancos na década de 1990 e início da década de 2000. Tal processo é explicado pelo "Relatório consolidado de 1988 a 2000" do Banco Central ${ }^{3}$ e por analistas econômicos (Camara et al., 2009; Alexandre; Lima \& Canuto, 2005) como: fruto do aumento exagerado de bancos após a Constituição de 1988; pelo fundamento da operação desses bancos serem o processo inflacionário da época; pela posterior política de combate à inflação do Plano Real; e a abertura financeira realizada na década de 1990, aumentando a concorrência no setor. Também é importante relembrarmos o Proer (Programa de estímulo à reestruturação e ao fortalecimento do sistema financeiro nacional), realizado no período FHC, que estimulou o processo de fusões e aquisições no setor bancário (Mick, 1998), bem como as políticas de privatizações que eliminaram diversos bancos públicos dos estados da Federação.

A situação do setor bancário, logo após à promulgação da Constituição de 1988, foi de aumento generalizado de bancos, que se beneficiavam de possibilidades legais de concessão de funcionamento e também da situação econômica hiperinflacionária. Tanto os novos bancos como os velhos se encaixaram no padrão de funcionamento financeiro dessa situação econômica. Medidas do governo que combateram a inflação, bem como um programa de reestruturação do setor (que incentivou o processo de fusão dos bancos), geraram a diminuição do número total de bancos, ou seja, produziram a centralização do capital no setor.

O que queremos afirmar é que o processo de desrregionalização da representação dos

3 Disponível em: http://www.bcb.gov.br/htms/Deorf/e88-2000/texto.asp?idpai=relsfn19882000. Acesso em: 28 de junho de 2010. 
banqueiros deve ser pensado ao lado do processo de centralização bancária. Esta alterou a composição social da fração bancária. Devemos ter em conta que o processo de centralização bancária beneficiou os maiores bancos (que cresceram através da compra de bancos públicos e bancos de pequeno porte, além das fusões).

Como observamos no estudo de Amado (1998), as consequências do processo de centralização não refletiram apenas no aumento de determinados bancos em suas participações no mercado nacional. Essa centralização teve impacto no enfraquecimento, ou desaparecimento, de bancos regionais importantes, bem como nas compras, ou transferências dos nichos de mercado destes, de bancos de caráter mais central. A autora defende sua tese apontando para as compras do Banco Econômico pelo Excel, do Banco Banorte pelo Bandeirantes e a compra do Banco Bamerindus pelo HSBC (Amado, 1998: 1127).

Com isso não queremos dizer que o sistema financeiro se espalhou igualmente para todas as regiões do Brasil. Atualmente, existem cadastrados no Banco Central 158 bancos. Destes, 106 possuem sua sede no Estado de São Paulo e 87 especificamente na cidade de São Paulo. ${ }^{4}$ Existe uma concentração de bancos em São Paulo. A atividade financeira no Brasil está centralizada nesse Estado. O que colocamos é que essa centralidade não se traduz em forças bancárias regionalizadas e que, portanto, exigiriam representatividade específica. ${ }^{5}$

Percebemos, primeiro, que o espaço de socialização dos banqueiros se modificou ao longo dos anos 1990 e 2000. Pelo fato de atores envolvidos tornarem-se mais nacionalizados em suas atividades, mais centralizados em suas matrizes (São Paulo), e em menor número, o associativismo desenvolveu esse aspecto mais nacionalizado e definido na FEBRABAN. E segundo, que esse processo de mudança ocorreu, pelo menos no nível associativo, de uma forma bastante coesa e sem grandes conflitos (mesmo que as mudanças econômicas no setor financeiro tenham sido extremamente predatórias para vários atores importantes da área).

\section{Estrutura institucional da FEBRABAN}

Para debater a estrutura institucional da FEBRABAN, traçamos como recorte temporal o ano de 2009. Escolhemos esse ano específico por motivos de fontes disponíveis.

4 Dados disponíveis no cadastro do Banco Central. Disponível em: http://www.bcb.gov.br/?RELINST. Acesso em: 27/08/2014. Esses números aumentaram em São Paulo a cada atualização que fizemos após a conclusão da dissertação.

5 Talvez essa centralidade possa ser justamente o motivo da não existência de forças bancárias mais regionalizadas. Tal conclusão pode ajudar no levantamento da hipótese de uma hegemonização do capital bancário paulista sobre o resto do capital bancário brasileiro. Mas isso seria debate para uma pesquisa específica. 
A FEBRABAN possuiu como publicação regular da instituição durante a década de 2000 os chamados "relatórios sociais". Esses relatórios possuem uma periodicidade anual e seu principal conteúdo se refere aos programas sociais financiados pelos bancos. ${ }^{6}$

Em 2009 o relatório social assumiu um caráter diferente. Nesse, foi discutida intensamente a estrutura institucional da entidade, sendo apresentados organogramas, cargos e membros da instituição, além de ser discutido o processo de abertura institucional da entidade. Sendo assim, focaremos na análise dos dados desse ano específico.

Nesse ano, existiam ao todo 125 bancos associados à FEBRABAN, de um total de 178 registrados no Banco Central. Tal número de afiliados é usado dentro do relatório social como argumento para afirmar que a FEBRABAN é a principal entidade representativa do setor bancário no Brasil. Portanto, existe a autoproclamação de sua maior relevância, enquanto instituição representativa, se comparada com as outras (FEBRABAN, 2009: 5).

6 Em geral, não discutem conteúdos políticos como comentários sobre a política estatal ou posicionamentos políticos mais gerais em relação à cena política. 
O organograma apresentado nesse relatório social é o seguinte:

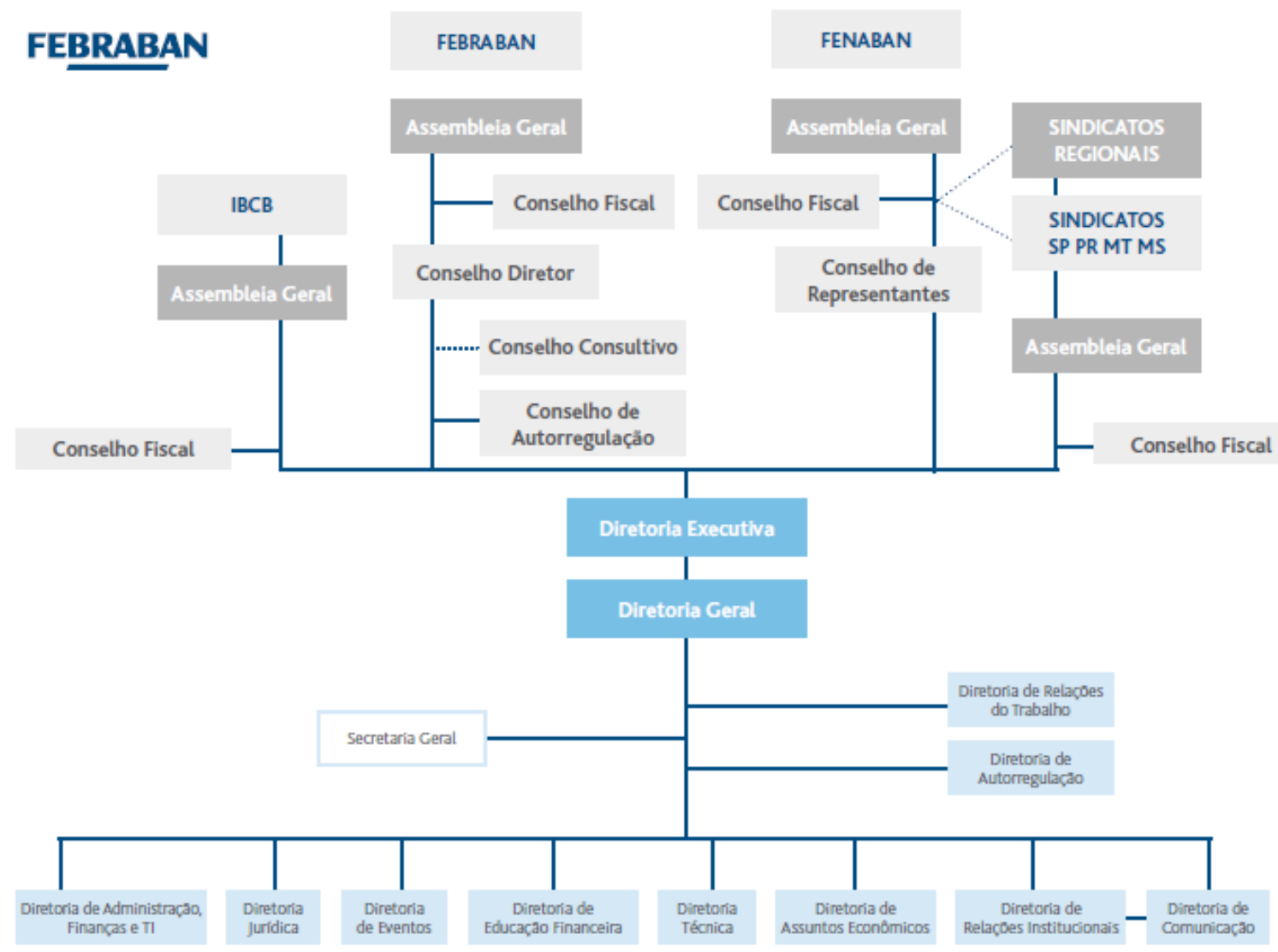

Fonte: FEBRABAN, 2009: 11.

A primeira característica importante que o organograma acima apresenta é a fusão existente entre três instituições: a FEBRABAN, a FENABAN e o IBCB (Instituto Brasileiro de Ciências Bancárias). A última instituição, segundo o site da FEBRABAN, é apenas um instituto criado com a finalidade de produzir material técnico sobre assuntos relacionados à atividade bancária, não sendo exatamente uma associação. A fusão realmente relevante para pensarmos o associativismo dos banqueiros é em relação à FEBRABAN e a FENABAN.

7 Disponível em: http://www.febraban.org.br/Febraban.asp?id_pagina=100. Acesso em: 15/02/2012. 
Por causa da estrutura sindical brasileira, as diversas camadas de empresários no Brasil possuem duas formas distintas de associativismo: a associação civil e a associação sindical. No caso da fração comercial, podemos observar essa distinção na Associação Comercial do Estado de São Paulo e da Federação do Comércio do Estado de São Paulo, estudada por Costa (2003). Também observamos tal distinção na fração industrial entre a Federação das Indústrias de São Paulo (FIESP) e o Centro das Indústrias do Estado de São Paulo (CIESP), que foi estudada por Toledo (2009).

A estrutura sindical brasileira exige a criação de uma entidade patronal específica para lidar com o relacionamento com os trabalhadores, e isso resulta na criação, por parte dos empresários brasileiros, de um duplo tipo de associativismo (um civil e outro sindical). Essas associações distintas estabelecem entre si uma relação específica e que devem ser estudadas caso a caso.

No caso dos banqueiros, percebemos que esse duplo associativismo, no processo de construção da representação nacional (tratada no segundo tópico do artigo), revelava uma polaridade regional de poder. Minella destaca que a FEBRABAN era controlada pela ASSOBESP, ou seja, pelos paulistas, e a FENABAN era controlada pela SBERJ, ou seja, pelos cariocas. Essa divisão jurídica refletia as polaridades regionais da representação dos banqueiros.

Como pudemos observar no terceiro tópico do artigo, essas forças regionais perderam força no período, e é isso que a situação de fusão entre FEBRABAN e FENABAN revela. O processo que gerou tal fusão pode ser remontado desde a década de 1980, com a mudança de sede da FENABAN para São Paulo no ano de 1983 (FEBRABAN, 2007: 79), e nas publicações que as entidades passaram a realizar conjuntamente.

O processo de fusão das instituições pode ser tema de uma pesquisa específica, mas o que queremos destacar é que as instituições são fundidas. Tal fusão demonstra duas coisas: o apaziguamento da polarização de poder entre cariocas e paulistas; e também que, no associativismo bancário, a solução para o problema gerado pela legislação sindical foi a fusão entre os dois tipos de entidades. A fala de Roberto Konder Bornhauser, presidente da FEBRABAN entre 1983 e 1986, demonstra essa propensão à unificação:

Olha, tem que unificar as duas entidades. Não dá para um ficar falando aqui, o outro falando lá, e o governo ficar jogando um pra cá, outro pra lá. Precisamos unificar. Tem que existir as duas, porque uma é sindical, e outra é civil, mas unifica (FEBRABAN, 2007: 79). 
A divisão em duas entidades seria motivo de desunião entre os banqueiros, o que prejudicaria até mesmo a relação com o Estado. A forma encontrada pelos banqueiros para solucionar esse problema foi a fusão organizacional das duas entidades. Como percebemos no organograma, as duas entidades possuem Assembleias Gerais próprias, mas todo o corpo administrativo corrente está vinculado à mesma diretoria executiva.

Nesse processo de fusão, consideramos que quem prevaleceu foi a forma civil de associativismo. A principal evidência nesse sentido é que a diretoria executiva é eleita durante as Assembleias Gerais da FEBRABAN. Ou seja, o corpo que administra as duas entidades é definido na Assembleia Geral de uma das entidades. Outra evidência é a própria autoproclamação da FEBRABAN como principal entidade do setor. Levando em consideração o nível de fusão das duas entidades, uma delas proclamar-se a principal também indica a prevalência do associativismo civil.

Essa "vitória" da forma associativa civil deve ser analisada levando em consideração a base que compunha este tipo de associação no período mais regionalizado de representação. Essa prevalência deve ser interpretada a partir da relação histórica estabelecida entre os banqueiros paulistas e cariocas durante a construção e consolidação das associações representativas nacionais. Nesse sentido, pensar em uma sobreposição da organização civil é também pensar em uma preponderância dos banqueiros paulistas no processo de desrregionalização.

Mas mais do que as razões dessa prevalência, também temos que refletir sobre as consequências do associativismo civil para o tipo de espaço representativo que se estabelece entre os banqueiros. Enquanto a finalidade organizacional do associativismo sindical possui um direcionamento mais específico (relação com os trabalhadores), percebemos que os objetivos do associativismo civil são mais abertos, indefinidos. Além dos objetivos, tal associativismo não recebe a contribuição compulsória das empresas. A contribuição para o associativismo sindical é definida por lei; já a contribuição para as associações civis é voluntária. O fato de a associação civil, que depende da vontade dos bancos para se financiar, prevalecer é outro fator importante para pensar o associativismo como um espaço importante de sociabilidade entre os banqueiros.

Além dessa característica mais geral do associativismo dos bancos, o organograma também mostra a estrutura diretiva e administrativa da FEBRABAN. 
A composição diretiva da FEBRABAN possui como instância superior de decisão as Assembleias Gerais. As Assembleias Gerais ordinárias ocorrem anualmente, e as extraordinárias ocorrem sem periodicidade definida (nossa pesquisa não conseguiu encontrar nenhuma assembleia extraordinária após 2006; antes disso havia uma regularidade anual destas, com exceção de 2004, ano no qual houve duas assembleias extraordinárias).

Abaixo dessa instância, existe uma estrutura administrativa regular da instituição. Os dois principais espaços da entidade são: o conselho diretor (composto pelos presidentes dos bancos associados, eleitos de três em três anos) e a diretoria executiva (composta por administradores de alto cargo dentro dos bancos associados, também eleitos). A primeira instância é um órgão consultivo, com um grau maior de hierarquia, mas que possui suas reuniões com uma periodicidade menor que as da diretoria executiva. A segunda possui um grau mais abaixo da hierarquia institucional, mas é a responsável pela gestão das atividades cotidianas da federação.

De qualquer forma, essas duas instâncias congregam o alto escalão de funcionários do sistema bancário brasileiro. $O$ fato de esse alto escalão participar regularmente de tais atividades associativas, ao lado do financiamento voluntário, sustenta a tese de que o espaço associativo da FEBRABAN é muito importante para os banqueiros.

A diretoria geral e as outras instâncias administrativas abaixo dela são compostas principalmente por funcionários da entidade, sem ser necessário o vínculo com algum banco específico.

O que existe dentro da FEBRABAN que relaciona membros dos bancos de menor escalão (sem a exigibilidade de ser presidente ou vice do banco) são os chamados Comitês Executivos ou Comissões Técnicas. No relatório social de 2009 as atribuições de tais instâncias são definidas genericamente por: "desenvolvem estudos que orientam as atividades da FEBRABAN" (FEBRABAN, 2009: 10). Diferentemente das outras instâncias administrativas, os componentes de tais Comissões são representantes de bancos, como podemos observar na listagem abaixo: 


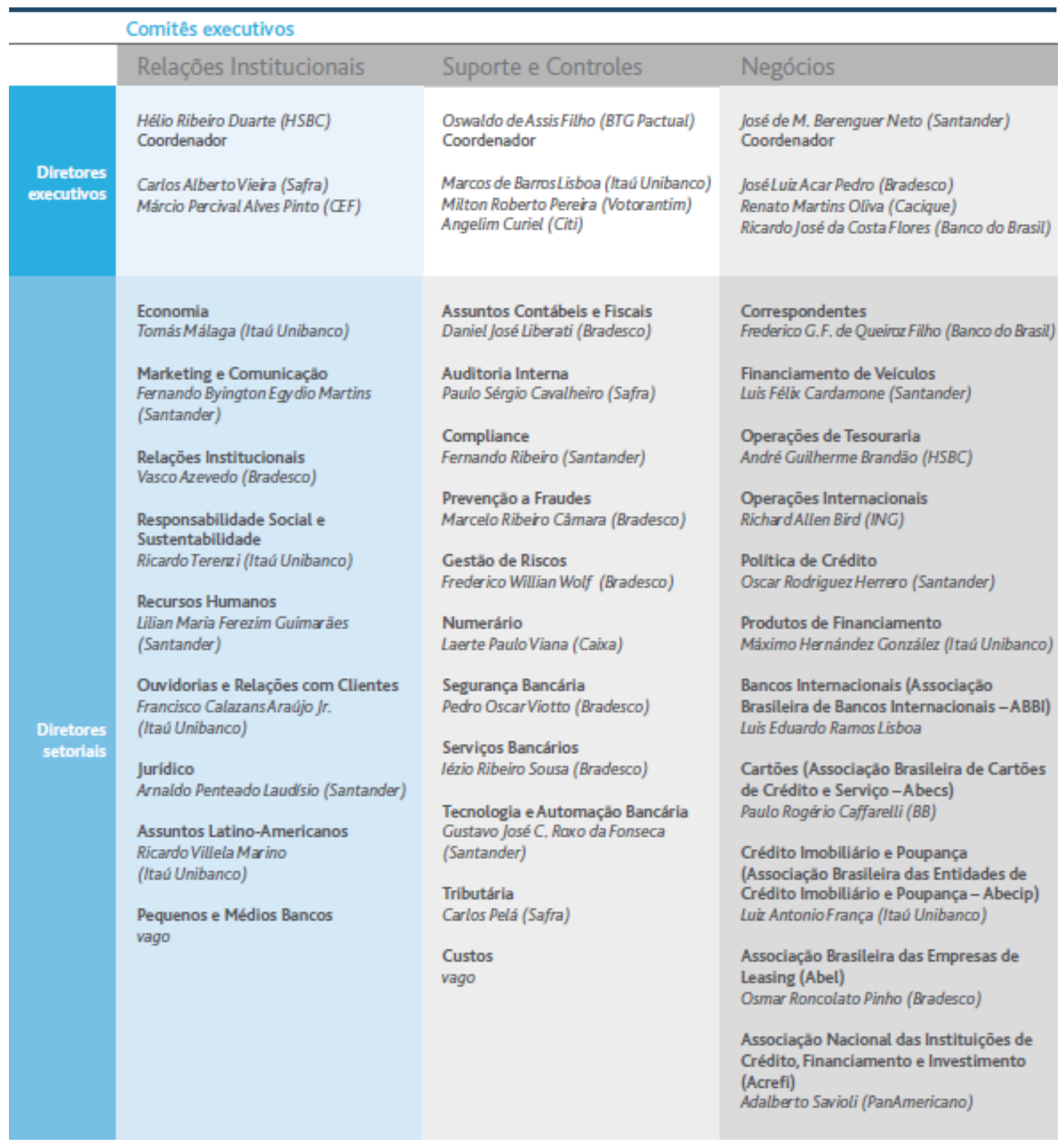

Fonte: FEBRABAN, 2009: 10

A primeira coisa que observamos nessa tabela é a heterogeneidade da composição das diretorias executivas dos comitês. Encontramos representados bancos públicos, privados, de grande e pequeno porte, de origem nacional e estrangeira.

Já na composição das diretorias setoriais não encontramos a mesma heterogeneidade. Especificamente nas de "Relações institucionais" e de "Suporte e controle", 
encontramos forte presença de três bancos específicos: Itaú, Bradesco e Santander. Esses três são os principais bancos privados de varejo no Brasil. ${ }^{8}$

Também percebemos que a composição das diretorias setoriais do Comitê de "Negócios" possui a presença de representantes de outras associações ligadas ao sistema financeiro, indicando que esse comitê seria um espaço para a construção de relações entre a FEBRABAN e outras entidades representativas do setor financeiro (o que poderia indicar uma organização do setor financeiro como um todo).

Uma análise mais detalhada desses espaços exigiria fontes que indicassem quais são especificamente as relações sociais e a produção prática de tais Comitês, sendo, portanto, tema para futuras pesquisas.

O que podemos indicar desde já é que existem espaços dentro da FEBRABAN nos quais tanto os representantes de grau hierárquico superior (presidentes e vice-presidentes) como os de grau hierárquico inferior podem se relacionar. Dessa forma, a FEBRABAN é um espaço no qual os banqueiros podem se socializar.

Uma última consideração a respeito da estrutura institucional da FEBRABAN é acerca da criação do Conselho Consultivo e do Conselho de Autorregulação, no ano de 2008. Estas são instâncias que estão localizadas acima da estrutura administrativa cotidiana da entidade, caracterizando-se mais pelo aspecto supervisor.

O intuito dos dois conselhos é a incorporação de representantes de outros setores sociais, dentro de instâncias decisórias da FEBRABAN. O Conselho Consultivo é apenas definido genericamente no relatório social como uma "boa prática dentro de associações civis" ao abrir o processo decisório da instituição para outros setores sociais. Esse seria um outro tema de pesquisa que poderia ser explorado pelo debate sobre como a governança corporativa está sendo incorporada pelos bancos e por suas associações representativas.

Já o Conselho de Autorregulação, que também possui membros de outros setores, tem seu papel mais definido. Ele se encarrega de monitorar o "sistema de autorregulação" que existe dentro da FEBRABAN. Esse sistema consistiria na formulação de certo "padrão de conduta" que deveria ser adotado entre os bancos (FEBRABAN, 2009: 27).

8 Pela ordem, Banco do Brasil em primeiro lugar, Itaú em segundo, Bradesco em terceiro, Santander em quarto, e Caixa Econômica Federal em quinto. Em sexto lugar vem HSBC, que não possui nem metade das agências que a CEF possui. Disponível em: http://www.bcb.gov.br/htms/deorf/r201012/T3AB_Quadro\%2007\%20-\%20Institui\%C3\%A7\%C3\%B5es\%20com\%20 maiores\%20redes\%20de\%20ag\%C3\%AAncias\%20no\%20pa\%C3\%ADs\%20.pdf. Acesso em: 15/02/2012. 
Levando em consideração que um dos aspectos marcantes na formação do associativismo nacional dos bancos foi justamente a padronização de certos aspectos da atividade bancária, consideramos que tal objetivo histórico se cristalizou nessa atividade da FEBRABAN de regular o sistema bancário. Mostrando assim uma certa capacidade (ou tentativa, aqui não cabe definir se isso é bem sucedido ou não) do empresariado bancário em se autorregular.

O que a criação desses dois conselhos aponta é justamente um processo de incorporação de membros de outros setores sociais na FEBRABAN. Isso é uma variável importante, levando em consideração que a FEBRABAN está sendo estudada aqui como um espaço de socialização. Esse espaço vem se desenvolvendo para integrar não só os membros da fração bancária, como também membros de outros setores sociais.

Tal processo deve ser considerado levando em conta a dificuldade dos banqueiros em estabelecer uma hegemonia tanto fora como dentro do bloco no poder. ${ }^{9} \mathrm{~A}$ incorporação institucionalizada de membros de outras classes sociais (não estamos falando aqui de trabalhadores; são principalmente ou organizações empresariais, instituições de ensino e pesquisa, ou entidades beneficentes) revela a tentativa de produzir minimamente um consenso dentro do bloco no poder, através da socialização desses outros setores dentro do próprio espaço dos banqueiros.

\section{FEBRABAN enquanto espaço de socialização dos banqueiros}

Consideramos que é necessário pensar o processo representativo dos banqueiros de uma maneira diferenciada, se comparado com as outras frações da classe burguesa no Brasil. Foram raros os momentos em que identificamos a FEBRABAN se posicionando diretamente em relação a temas políticos de relevância. Inclusive, quando isso foi feito, por exemplo, quando Roberto Luís Troster criticou diretamente o governo, em duas semanas ele "se afastou" do cargo diante da crise política que gerou (discutimos esse acontecimento em nossa dissertação).

9 Esse debate foi mais explorado na versão completa de nossa dissertação de mestrado. FILGUEIRAS (2006) destaca a dificuldade por parte dos banqueiros em organizar um consenso dentro do bloco no poder. Identificamos essa tentativa de incorporação de outros setores sociais em instâncias decisórias da FEBRABAN como uma tentativa de amenizar essa dificuldade. 
Dois elementos são importantes de serem observados. Primeiro, que o impacto público de uma opinião por parte dos banqueiros é muito intenso, sendo essa uma ferramenta que deve ser usada com muito mais cautela, se comparada com os industriais, por exemplo. Segundo, que os bancos são instituições com um poder econômico muito grande, e o seu setor é muito mais centralizado, também em comparação com os industriais (é um número muito menor de instituições).

Ou seja, os bancos individualmente conseguem se fazer representar dentro da cena política. Por isso, em nossa pesquisa mais ampla, quando buscamos o posicionamento da fração bancária diante da política governamental, procuramos os pronunciamentos individuais. Por ter a capacidade de, individualmente, impactar na cena política do país, acreditamos que o principal interesse dos bancos ao se associarem não é "unir forças" para obter mais respaldo político; o sistema representativo dos banqueiros possui outra direção.

Consideramos que a criação de um espaço social capaz de criar interação entre os membros da fração bancária entre si, e também entre esses membros e outros setores sociais, é o principal produto do associativismo bancário no Brasil.

Tal objeto pode ser estudado através da metodologia de análise de redes sociais, já destacadas por Minella (2007) e Miranda (2005) como útil para a análise de banqueiros. Não desenvolvemos operacionalmente tal metodologia, mas desejamos destacar a potencialidade de tal método para a reflexão sobre a estrutura social desses empresários, e também sobre a ação política destes.

Com essa metodologia é possível mapear os laços construídos entre os banqueiros, o que poderia apontar potencialidades de comunicação entre as instituições bancárias. Mas, para a qualificação dessas relações, a utilização de entrevistas seria o método mais eficaz. Essa não foi a metodologia adotada sistematicamente em nossa dissertação, mas conseguimos realizar uma com Fernando Nogueira da Costa, ex-vice-presidente da Caixa Econômica Federal e ex-diretor executivo da FEBRABAN.

Tal entrevista apresentou pistas do caráter das relações estabelecidas entre os banqueiros. $O$ entrevistado mencionou que, entre os banqueiros, era comum a utilização do termo benchmarking para definir o tipo de relacionamento que eles estabeleciam entre si. A definição desse termo apresentada por Costa foi a seguinte: 
A consulta usual aos concorrentes para balizar ("copiar ou inspirar") os próprios projetos. Muitas vezes são realizadas via rede de relacionamentos pessoais entre os profissionais de menor escalão, inclusive os estabelecidos nas diversas Comissões da FEBRABAN.

Percebemos que, através de uma linguagem administrativa, os banqueiros destacam o papel importante que a troca de informações tem no relacionamento estabelecido entre os banqueiros dentro da FEBRABAN. Uma investigação mais sistemática do significado desse termo para os banqueiros seria necessária, mas essa definição já nos aponta a importância da troca de informações tanto entre os grandes líderes dos bancos como entre os funcionários de menor escalão, mostrando assim o tipo de relação social que é estabelecida dentro da entidade.

Mas, para além das relações intraclasse, a socialização dos banqueiros dentro do espaço associativo possui maiores implicações. A partir de 1998, os primeiros bancos públicos começaram a participar da diretoria executiva e do Conselho Diretor. É interessante pensarmos nessa entrada diante da conclusão de Mick (1998) da baixa capacidade dos banqueiros em influenciar algumas reformas financeiras da década de 1990, em específico o PROER.

A ideia de redes sociais nos permite pensar este ato, de introdução de bancos públicos, como um ato de expansão da rede social sobre a base de banqueiros presente no Brasil. Isso mostra que a representação bancária, enquanto espaço de socialização, é mais do que um relacionamento intraclasse; também é um relacionamento entre o setor bancário e o Estado.

É comum encontrarmos nos jornais banqueiros que já tiveram participação em algum ministério ou mesmo no Banco Central. Mas esse fluxo não está consolidado institucionalmente. É uma prática de fluxo de pessoas, que levam consigo seu conhecimento das instituições públicas e também seus contatos internos. Mas isso não fortalece os vínculos institucionais entre entidades públicas e privadas.

A absorção de bancos públicos dentro da FEBRABAN seria um avanço nas práticas de relacionamento direto com o Estado; significaria a institucionalização de tais práticas. E aqui podemos observar o nível de representatividade da entidade aumentando, ao incorporar novos banqueiros e possibilitar a criação de novas redes de sociabilidade. 
Portanto, um estudo que problematize a representatividade enquanto adesão orgânica dos representados na entidade é capaz de perceber como os banqueiros se distribuem dentro da FEBRABAN e, a partir disso, retirar inferências sobre a estrutura de relações e de ações dos banqueiros.

Refletindo acerca da pergunta inicial do artigo sobre qual papel a instituição representativa dos banqueiros possui, nossa pesquisa aponta o importante papel que a organização possui no processo de socialização da fração da classe bancária, socialização esta tanto interna como com outras frações da classe e também com o Estado.

\section{Referências bibliográficas}

ALEXANDRE, Michel; LIMA, Gilberto Tadeu; CANUTO, Otaviano. 2005. Distribuição espacial da atividade bancária no Brasil: dimensões e indicadores. Nova Economia: Belo Horizonte, $15[1]$.

AMADO, Adriana. 1998. Impactos regionais do recente processo de concentração bancária no Brasil. III Encontro Nacional de Economia Política.

BIANCHI, Alvaro. 2010. Um ministério dos industriais: a Federação das Indústrias do Estado de São Paulo na crise das décadas de 1980 e 1990. Campinas: Unicamp.

BOITO, Armando. 1998. Política neoliberal e sindicalismo no Brasil. Tese de livre docência. Instituto de Filosofia e Ciências Humanas: UNICAMP.

CAMARA, Marcia Regina Gabardo da et al. 2009. O abuso do poder econômico no setor bancário brasileiro. Apresentação ao 47o Congresso da Sociedade Brasileira de Economia, Administração e Sociologia Rural: Porto Alegre.

COSTA, Fernando Nogueira da. Brasil dos Bancos. 2012. São Paulo: Edusp.

COSTA, Paulo Roberto Neves. 2003. Empresariado e democracia no Brasil (1984-1994). Tese de Doutorado, Instituto de Filosofia e Ciências Humanas. São Paulo: UNICAMP.

FILGUEIRAS, Luiz. 2006. O neoliberalismo no Brasil: estrutura, dinâmica e ajuste do modelo econômico.In:BASUALDO, Eduardo;ARCEO, Enrique. Neoliberalismoysectores dominantes. Tendencias globales y experiencias nacionales. Buenos Aires: CLACSO, p. 179-206.

FONSECA, Marcelo Maciel da; BARBACHAN, Jose Santiago Fajardo. 2004. Concentração bancária brasileira: uma análise microeconômica. FINANCELAB Working Paper. Ibmec Educacional. 
GRAMSCl, Antonio. 2001. Cadernos do cárcere. São Paulo: Civilização Brasileira, v. 1.

KINZO, Maria D'alva Gil. 1978. Representação política: perspectivas teóricas e um exame da experiência brasileira. Tese de mestrado. PUC-SP.

MELLO, Alex Fiuza de. 2000. Capitalismo e mundialização em Marx. São Paulo: Perspectiva.

MICK, Jacques. 1998. A globalização financeira e as mudanças na regulamentação do sistema financeiro nacional (1994-1996): um estudo sob a perspectiva da hegemonia financeira. Dissertação e mestrado. Centro de Filosofia e Ciências Humanas, UFSC.

MINELLA, Ary Cesar. 1988. Banqueiros: organização e poder político no Brasil. Rio de Janeiro: Espaço e Tempo.

MIRANDA, Elflay. 2005. Federação brasileira de bancos: uma análise sociopolítica do período 1994-2001. Dissertação de mestrado. Centro de Filosofia e Ciências Humanas, UFSC.

NAKANE, Marcio; ROCHA, Bruno. 2010. Concentração, concorrência e rentabilidade no setor bancário brasileiro: uma visão atualizada. Tendências Consultoria Integrada. Trabalho disponível no acervo eletrônico da FEBRABAN.

Toledo, Demetrio Gaspari Cine de. 2009. As redes empresariais da elite industrial de São Paulo: FIESP - CIESP: 1992 - 2004. São Paulo: Papagaio.

\section{Documentos analisados}

FEBRABAN: Perfil Institucional. 2005.

FEBRABAN: Atas das assembleias gerais, 1989 - 2009.

FEBRABAN: Estatuto social, 1999.

FEBRABAN: Estatuto social, 2009.

FEBRABAN: 40 anos de participação, 2007.

Recebido: 10/11/2013

Aceito: 18/08/2014 